Article

\title{
An Integrated Approach for Eco-Design and Its Application in LED Lighting Product Development
}

\author{
Daizhong Su ${ }^{1, *(\mathbb{D}}$, Jose L. Casamayor ${ }^{2} \mathbb{( 1 )}$ and Xuemin $\mathrm{Xu}^{1}$ \\ 1 Advanced Design and Manufacturing Engineering Centre (ADMEC), School of Architecture, Design and the \\ Built Environment, Nottingham Trent University, Nottingham NG1 4FQ, UK; xuemin.xu2005@my.ntu.ac.uk \\ 2 Advanced Manufacturing Research Centre (AMRC), Sheffield University, Rotherham S60 5TZ, UK; \\ J.CasamayorAlarco@sheffield.ac.uk \\ * Correspondence: daizhong.su@ntu.ac.uk; Tel.: +44-(0)115-848-2306
}

check for updates

Citation: Su, D.; Casamayor, J.L.; Xu,

$X$. An Integrated Approach for Eco-Design and Its Application in LED Lighting Product Development. Sustainability 2021, 13, 488. https:// doi.org/10.3390/su13020488

Received: 2 December 2020

Accepted: 4 January 2021

Published: 6 January 2021

Publisher's Note: MDPI stays neutral with regard to jurisdictional clai$\mathrm{ms}$ in published maps and institutional affiliations.

Copyright: (C) 2021 by the authors. Licensee MDPI, Basel, Switzerland. This article is an open access article distributed under the terms and conditions of the Creative Commons Attribution (CC BY) license (https:// creativecommons.org/licenses/by/ $4.0 /)$.

\begin{abstract}
Lighting products are essential for our modern life nowadays, but they also produce high negative impacts on the environment. Although there are tools and methods available for reducing the environmental impact of lighting products, it is a challenging task to integrate them throughout the product development process. To overcome the challenge, this research developed an approach to integrate tools/methods relevant for the eco-design through product development process to reduce the environmental impact of lighting products. Six types of methods, such module design, and 30 tools, such as lifecycle assessment software packages, are considered in the integrated approach. The product specification with eco-constrains is established for implementation at each design stage to ensure the product eco-features. The approach was applied in the development of an LED table lamp which was then assessed in comparison with a benchmark LED lamp regarding environmental lifecycle impact and lighting performance. The comparative assessment results indicate that the LED lamp developed with this approach is much better than the benchmark lamp.
\end{abstract}

Keywords: eco-design; lighting product; life cycle assessment (LCA); integrated approach; product design specification; sustainable design; sustainable manufacture; environmental impact

\section{Introduction}

Lighting products are essential for our modern life nowadays. However, they also consume a large amount of resources and produce considerable harmful emissions. According to the United Nations Environment Programme, lighting contributes about 15\% of electricity consumption and $4.6 \%$ of greenhouse gas emissions in the world [1]. During the use phase, lighting products account for about $20 \%$ of global building electricity consumption [2]. These have resulted in high negative impacts on the environment and climate change. By 2030, the work of initiatives to mitigate the impacts is projected to deploy $50 \%$ more lighting globally while consuming 50\% less energy compared to today [3].

Design is the most important factor in reducing the product's impact on the environment [4], because over $80 \%$ of all product-related environmental impacts can be influenced during the design phase [5]. Similar statements can be found in many sources in the literature, for example, the publications by Olesen [6], Graedel, Comrie and Sekutowski [7], McAloone and Bey [8], Church [9] and more. Therefore, eco-design has been applied to reduce the lighting products' impact on the environment.

There has been a rich literature about the definition of eco-design. A simple definition of eco-design would be creating products considering their environmental impact during their entire "life": from their manufacturing process, to their use and their disposal [10]. Eco-design is further defined in [11] as both a principle and an approach. It consists of integrating environmental protection criteria over a service or a product's lifecycle. The main goal of eco-design is to anticipate and minimize negative environmental impacts (of manufacturing, using and disposing of products). Simultaneously, eco- design also keeps a 
product's quality level according to its ideal usage [11]. Charter [12] stated that eco-design is an integrative ecologically responsible design discipline. Eco-design can also be posited as the process within design and development of integration environmental consideration into product design and development with the aim of reducing environmental impacts of products through their life cycle. The official online channel for business advice and guidance in Northern Ireland [13] provided ten core environmental considerations at the heart of eco-design and advised that products or services should be evaluated according to these principles and their environmental impact, as well as the potential for improvement or change.

According to the above, this research considers the eco-design as a process to create products aiming at reducing environmental impacts through their life cycle and also keeping their quality level according to their ideal usage. In addition to product design specification, conceptual design and detail design, this process also includes prototyping, testing and manufacture, results of which validate the designed product.

Product design specification (PDS) is established at the beginning of the product design stage. It is a fundamental control mechanism that allows the success of the product development. The PDS methods and applications can be found in several well-known design publications. In the total design approach [14], PDS is a design core acting as the mantle or cloak that envelops all stages and controls the total design activity because it places boundaries on the subsequent designs; 32 PDS items are detailed and how to implement them through the total design process is explained. Ulrich and Eppinger [15] referred to PDS as product specifications and presented how to develop the specifications, including four steps to establish target specifications and five steps to set the final specifications. PDS is also defined as a requirement list utilised throughout the product development process [16,17].

Although the PDS method has been utilised in product design for many years, the incorporation of reducing product impact on the environment in the PDS has not been given enough attention. To address this issue, this research has developed eco-PDS for lighting products, which specially focuses on the product's impact on the environment and is utilised in the development of lighting products.

There are several studies published in eco-design of lighting products. For example, Zehra, Korkmaz and Ahmeda [18] conducted research in sustainable lighting systems for university buildings. Balocco and Volante [19] considered a museum environment as a case study to implement a lighting design system to reduce energy consumption, whilst enhancing information and perception. Klaassen, et al. [20] investigated the eco-efficient value creation of residential street lighting systems by simultaneously analysing the value, costs and eco-costs during the design and engineering phase. Wang, et al [21] conducted the life cycle assessment of five domestic lighting products existing in the market, and, based on the assessment results, a new sustainable lamp was developed. Richter, Tähkämö and Dalhammar [22] investigated the trade-offs with longer lifetimes of LED lamps considering product development and energy contexts. Shahzada, K., et al [23] investigated three types of street lighting luminaires (high pressure sodium, compact fluorescent and LED), using Sustainable Process Index and LCA methods, and concluded that the LED luminaires were more environmentally friendly in terms of carbon footprints and energy consumption. Katzin, et al. [24] conducted a study for energy savings in greenhouses by transition from high-pressure sodium to LED lighting. Zhang, K., et al. [25] proposed an economics strategy for criticality with an application to the rare earth element Yttrium in new lighting technology and its sustainable availability.

The literature review reveals that although there has been research conducted in various areas related to environmental impact of lighting products, a comprehensive study about the eco-design of LED lighting products has not been sufficiently investigated.

To address the issues identified above, an integrated approach for eco-design of LED lighting products is developed by this research, which covers all stages of the product 
development process including design, prototyping, testing and manufacture. The eco-PDS is implemented at each stage within the lighting product development process.

In the following sections of this paper, the integrated approach for eco-design of lighting products and the eco-PDS development are presented first, and then applied into the development of an LED table lamp. Finally, a comparative assessment of the developed LED table lamp using life cycle analysis and other performance criteria, e.g., luminous efficacy, energy consumption is conducted to compare its environmental impact, light performance, and energy efficiency-efficacy with a benchmark LED table lamp made by the same manufacturing company. The results show that the new LED table lamp developed in this study reduced its environmental impact and achieved higher efficacy and energy-efficiency values compared with the benchmark LED table lamp, indicating the success of the integrated approach and the eco-PDS method.

\section{Research Methods}

\subsection{The Integrated Approach for Eco-Design}

\subsubsection{Methods and Tools Considered in the Integrated Approach}

Although there are tools and methods available for reducing the environmental impact of lighting products, it is a challenging task to integrate them throughout the product development process including design, prototyping, test and manufacture. To overcome the challenge, this research developed an approach to integrate tools/methods relevant for the eco-design of lighting products, as shown in Figure 1. The methods and tools selection are based on its relevance to support the assessment (e.g., assessment-related tools and methods) and reduction (design related tools and methods) in the environmental impact of LED-based lighting products. In addition to the selection criteria, they are also selected based on their effectiveness (e.g., results accuracy, consistency and reliability), after short trials with all the available methods and tools relevant to this area.
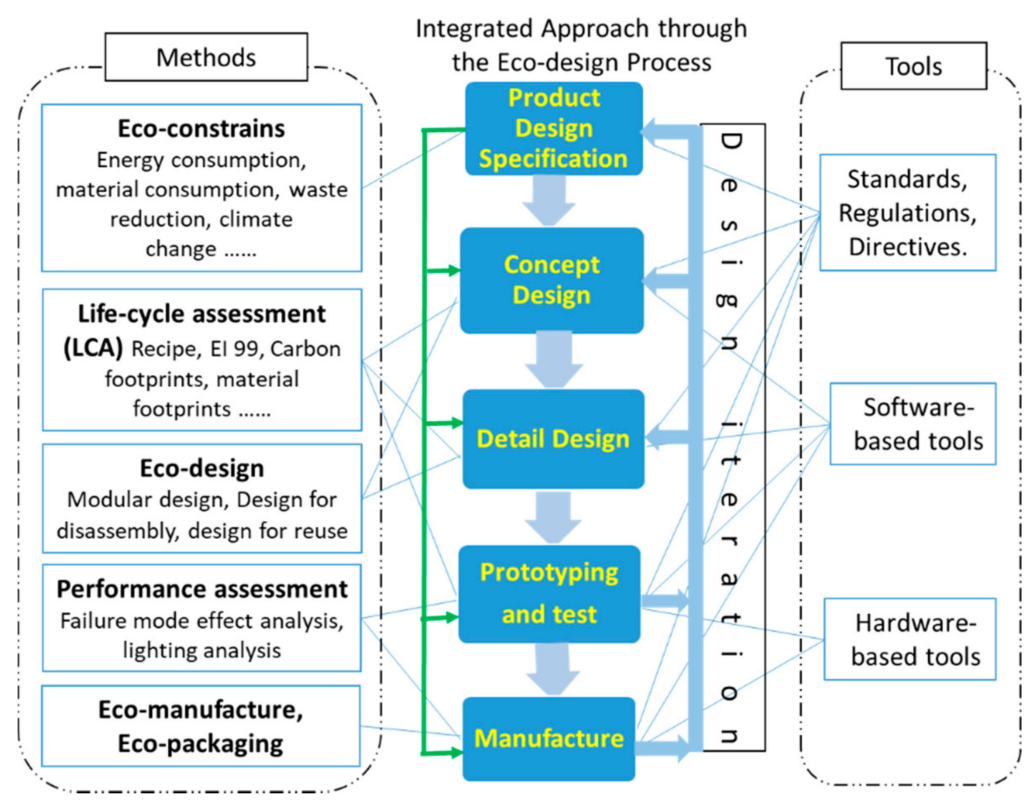

Figure 1. Integration of relevant tools and methods within the eco-design process.

The methods considered for product eco-design in this approach include:

- Elaboration of product design specifications with eco-constrains, such as reduction in product carbon footprints, energy/material consumption, waste, contribution to climate change.

- Product lifecycle impact assessment methods, such as Recipe, EI-99 and material footprints.

- Product failure analyses, such as failure mode, effect and criticality analyses. 
- Eco-design methods, such as modular design, design for repair, design for recycling, and design for disassembly

- Eco-manufacture and eco-packaging.

The tools considered for product eco-design in this approach include:

- Regulations, directives and standards related to product eco-design, for example, directive 2012/19/EU ‘Waste electrical and electronic equipment (WEEE) [26] (European Commission, 2012)'. Standards related to LED and lighting, for example, standard 'UL8750-2009: Light Emitting Diode (LED) Equipment for Use in Lighting Products' [27].

- Software-based tools are used for selection of LED chips and life cycle assessment (LCA) software packages, such as SimaPro [28].

- Light analysis/measurement tools are used to validate/confirm the efficient light performance (light quantity/quality and power consumption) of the LED lighting product, for example, goniophotometer [29].

More information about the above tools can be found in [30], which presents two regulations, nine directives and 26 standards related to product eco-design, and [31] which contains 13 standards related to LED and lighting, 7 software tools, and 9 light analysis and measurement tools.

\subsubsection{The Integrated Approach}

The approach covers several stages including the elaboration of Product Design Specification (PDS), concept design, detail design, prototyping, testing and manufacture, as illustrated in Figure 1.

In the PDS elaboration stage, eco-constrains are derived from various sources such as relevant directives, regulations, eco-design guidelines, standards, etc. These eco-constrains are incorporated into the PDS.

In the conceptual design stage, to meet the PDS elaborated in the previous phase, design concepts are generated and then evaluated against the PDS evaluation criteria.

In the detail design stage, the product is further developed from the concept obtained in the conceptual design phase. The major tasks include selection of components (e.g., LED chips, heat sink, and LED driver), materials selection, and product configuration. Several software tools are utilized to select components and conduct the detail design. Relevant standards are also referred to during this stage of the process to ensure the product quality and to meet the PDS.

In the prototyping and testing stage, the prototype of the product is produced and tested, proper testing equipment is utilized to test the product performance. The LCA methods, ecodesign methods and product failure analysis methods, which are mentioned in Figure 1, are utilized in this phase. A comprehensive LCA is conducted at this stage, and a suitable LCA software, such as Simapro, is utilized.

In the manufacturing stage, relevant eco-manufacturing and eco-packaging methods are applied to reduce waste, material, energy consumption, and impact on the environment. Relevant standards are also followed at this stage to ensure product quality.

\subsection{Eco-Product Design Specifications (eco-PDS)}

The product design specification (PDS) plays an important role in the product development. The PDS has to be met at each stage of the product development. In other words, the PDS is a control mechanism to ensure the product to achieve the expected function [8]. Therefore, it is necessary for the PDS to include the eco-features of the product, i.e., eco-PDS, in order to ensure that the product reduces its impact on the environment. The PDS selected for this study were based on a summary of the relevant PDS applicable to the specific LED-based lighting product of this case study, and were obtained from existing best practices from handbooks, books, academic papers and relevant directives, regulations and standards. 
In this research, the following eco-PDS items are specified during the PDS configuration stage:

- The product should use as small a number of components as possible, whilst maintaining the required functions.

- Extend the product lifespan. The product should be durable, and its components should have easy access for repair.

- Apply eco-design methods, such as modular design, design for easy repair and upgrade, design for disassembly, design for reuse, etc.

- Facilitate easy disassembly such as less number and types of joints used in the product, and avoid special tools for disassembly and non-detachable joints (welded or glued joints).

- Use the minimum type of materials, which facilitates the sorting of components for reuse and recycling when the product reaches its end of service life.

- Avoid the use of (1) sticker-labels on the product materials, (2) finishes in materials, and (3) toxic materials.

- Use low environmental impact materials and manufacturing processes.

- Conduct life cycle impact assessment in order to reduce product's negative impacts.

- Comply with regulations, directives and standards related to eco-design of products

- Enable eco-manufacture.

To establish the eco-PDS, relevant directives, regulations and standards are considered. For example, the 'Restriction of Hazardous Substances (RoHS) directive' restricts the use of six hazardous materials: Lead $(\mathrm{Pb})$, Mercury $(\mathrm{Hg})$, Cadmium $(\mathrm{Cd})$, Hexavalent chromium (Cr6+), Polybrominated biphenyls (PBB) and Polybrominated diphenyl ether (PBDE) in the manufacture of various types of electronic and electrical equipment. Derived from this directive, the 'avoidance of using toxic materials' is specified in the PDS, and all the components (e.g., LEDs, driver, circuit), including their finishing processes used in the lighting product to comply with RoHS.

\section{Development of the LED Table Lamp by Utilizing the Integrated Approach}

The LED table lamp shown in Figure 2 was developed using the integrated approach, as a demonstrator of the EU FP7 cycLED project [32]. This product was manufactured by Ona Product S. L., a lighting product manufacturer in Spain, and is now available at the company's online shop [33].

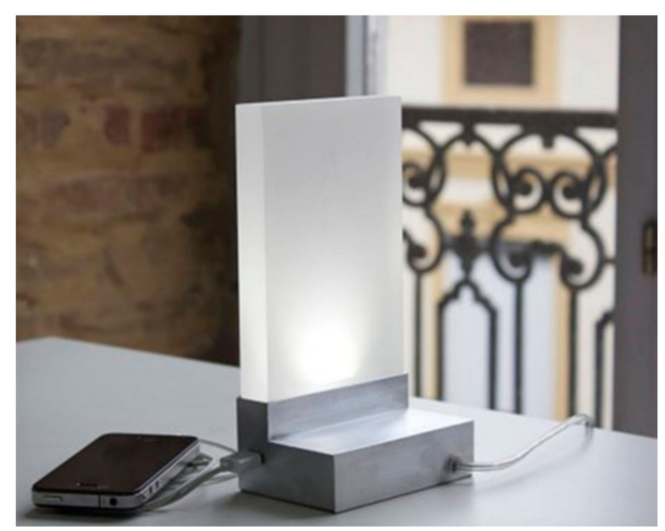

Figure 2. The LED table lamp developed by this research [33].

In this section, the above-mentioned LED table lamp is used to illustrate how the integrated approach presented in Section 2 is applied in the process of developing an LED lighting product. 


\subsection{Conceptual Design}

Following the total design method [14] and market demands, the concept of the LED table lamp was developed, as shown in Figure 3. Because it is a design concept, detailed structure and dimensions are to be determined at the detail design stage. In addition to traditional PDS, such as those stated in [14-17], the product concept was developed also in compliance with the eco-PDS presented in Section 2.2.

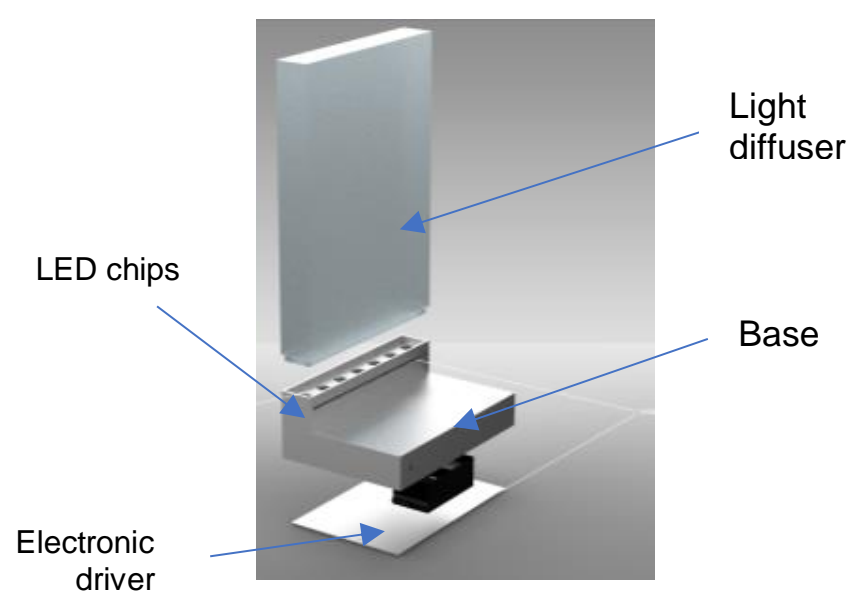

Figure 3. CAD model of the LED table lamp concept.

In the following context, each eco-PDS is shown in italics, followed by explanations how the conceptual design complies with the eco-PDS.

Use fewer components: The product is made of 3 main parts, and the architecture of the product is very simple, which make it easy to dismantle for repair, and/or recycle.

Increase product lifespan: Several strategies have been implemented to increase the product lifespan: (1) Increase the reliability of the product, (2) design the product for easy disassembly, (3) long warranty, (4) design a system to incentivize the return of products, (5) Register with WEEE to facilitate recycling and (6) informing the consumer how to use, repair and where to dispose the product for recycling.

Use recycled materials: The main materials used in the product are aluminum and PMMA. The aluminum is $100 \%$ from recycled aluminum.

Improve the energy-efficiency of the product: The LED driver has been selected to optimally function with the LED, to save energy and extend lifespan. Energy-efficient light sources have been used.

Use the minimum type of different materials: The number of materials used in the product have been reduced to 2 main materials (in the housing) for easy separation.

Application of eco-design methods/principles: (1) Design for disassembly: The product has a basic architecture with three main parts, including light diffuser, base and electronic set (LED, electronic driver and assessors), which facilitate disassembly for recycling. It uses eight screws that can be dismantled to have access to all internal components without breaking the product (non-destructive disassembly). It can be dismantled with a common screwdriver. (2) Design for easy repair and upgrade: The product's simple architecture with few parts facilitates easy disassembly. It does not use non-detachable joints so the product can be dismantled, repaired and assembled again without breaking the product (nondestructive disassembly). It is easy to access the electrical-electronic components that may fail or become out of date. (3) Use standard components, and provide product structure and disassembly information with suppliers' name and component ref. to consumers to facilitate repair and upgrade outside the warranty period.

Avoid several issues in order to comply with the eco-PDS: (1) Avoid the use of special tools for disassembly: The only tool required for disassembly of the product is a commonly used screwdriver. (2) Avoid non-detachable joints (welded or glued joints): All the joints used 
in the product are detachable, so the product can be dismantled without breaking it (nondestructive disassembly). (3) Avoid the use of labels: Labels are not used on the product and the packaging, which facilitates recycling of the materials. (4) Avoid the use of finishes on the materials: The materials used have no additional coating, which facilitates recycling.

Reduce the weight and volume of the product and packaging: The volume of the product is quite small, and the total weight is $601 \mathrm{~g}$. This contributes to reduce the impact caused during distribution. The geometry of the product also facilitates packing more products within the same volume, which also reduces the impact in the distribution stage.

Compliance with eco-regulations and eco-directives including (1) Energy labelling directive (2010/30/EU) [34]: The packaging of the luminaire provides information about energy consumption, light output performance, and useful lifetime of the light sources used. (2) Restriction of Hazardous Substances (RoHS) directive [35]: The product and all the components included comply with RoHS directive. (3) The Eco-design directive (2009/125/EC) [36]: The LED driver-LED system has been optimized to save energy, and energy-efficient light sources have been used. In terms of materials, the lifespan of the product has been extended, it has been applied into the design of the product so it is easy to dismantle to facilitate easy repair, upgrade and recycling. Recycled aluminum material is used to make the base, recyclable plastic material is used to make the casing, and both the components are recyclable.

\subsection{Detail Design}

In the detail design stage, the design complies with the eco-PDS, and relevant software is utilized to conduct the detail design. Figure 4 shows the table lamp that resulted from the detail design.

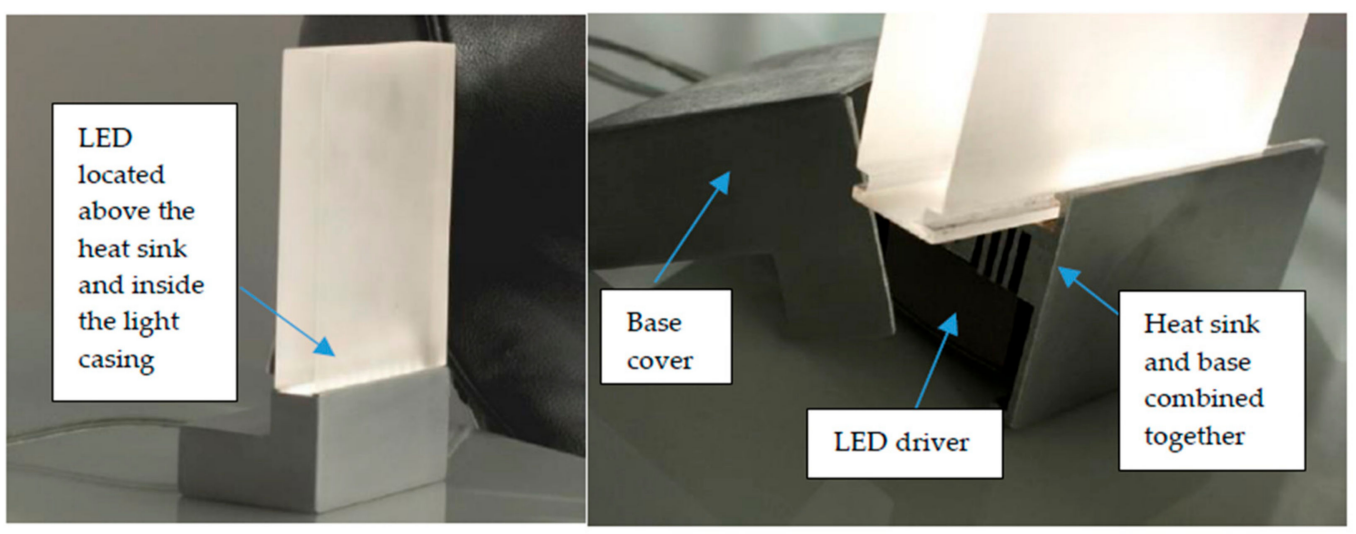

Figure 4. The LED table lamp prototype manufactured after detail design.

\subsubsection{Compliance with the eco-PDS}

Due to the limitation on the length of this paper, only selected eco-PDS items are mentioned in this sub-section as follows (the eco-PDS is shown in italics, followed by explanations how the design complies with the eco-PDS).

Specify reliable components from well-known suppliers: LEDs and LED drivers have been outsourced from well-known suppliers (Samsung supplied the LEDs, and Lumotech supplied the LED driver), and the models selected have passed rigorous reliability tests and servicing for these components is assured with following well established suppliers.

- $\quad$ LEDs specifications: LED chips, Samsung LM561A—5630 Middle Power LED [37].

- Driver specifications: Lumotech, LEDlight Micro series-L05050/L05150 [38].

The driver features a series of properties that contribute to extend its lifespan and its energy-efficiency (and the whole luminaire): Open circuit protection, overload, over voltage and over temperature protection, high power factor (0.91), Future-proof flexibility: industry 
leading output voltage range enabling seamless support of LED generations and minimizing supply chain complexity. The warranty is 5 years (around 50,000 operative hours), in order to match the LED long lifespan $(50,000 \mathrm{~h}$.).

The LED chips have passed rigorous reliability tests and are PB free and comply with RoHS [35] and REACH [39].

Reduce the number of joints: The product only has three joints to join the three main parts (diffuser, heat sink and casing). These three parts are joined by pressure-fit. These will enable not only easy assembly, but also easy disassembly of the product when the product reaches its end of life (EoL).

Reduce the type of joints: All the joints used are the same type (e.g., pressure-fit), which avoids the need of using different tools for disassembly to make disassembly easier to enable easy to repair the product or to recycle the product when it reaches its EoL stage.

Integration functions: The base, which is a main part of the lamp, is made of aluminum and also functions as heat sink. This is an example of integration of two functions from two components in one component, which saves material and energy typically used in the manufacturing of new parts, and hence reduces the impact on the environment.

The product should have easy/fast disassembly: The initial structure (Figure 5) of the product was revised and optimized to reduce the number of disassembly steps, joints and components. Screws have been eliminated and all the parts are now assembled by pressure-fit. This easy/fast disassembly feature enables easy repair of the product or recycling of the product when it reaches the EoL.

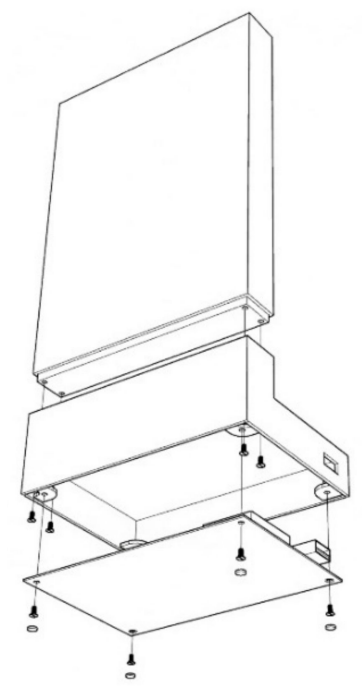

Figure 5. Initial structure of the LED table lamp.

Compliance with standards: LEDs and drivers selected from suppliers should have passed the highest standard possible. The following standards are utilised to double check the quality of the components selected from suppliers. (1) British standards EN55015 [40], EN61000-3-2 [41], EN61347-2-13 [42], EN61347-1 [43], EN61547 [44] and EN62384 [45]: These standards are related with reliability and safety of drivers. Some of these are required to comply with the basic CE label for devices that have to be commercialized in the EU, and others specify performance requirements that can be over the standards required. The LED driver selected (Lumotech LEDlight Micro series-L05050/L05150) complies with all the standards mentioned above and presents some advanced features which make the driver (and hence the whole lighting system) more reliable and long lasting. The advanced features achieved include short and open circuit protection, overload and over voltage protection, Safety Extra Low Voltage (SELV), future-proof flexibility, and industry leading output voltage range enabling seamless support of LED generations and minimizing supply chain complexity. (2) IES-LM-80 [46] and IES-TM-21 [47]: These are standards and methods for testing the estimated lifespan of LEDs. LEDs have to be outsourced from 
suppliers that provide lifespan data based on these standards in order for the results to be reliable and comparable with other suppliers. The LEDs selected (Samsung LM 561A-5630 middle power LED) provided performance datasheets based on these standards.

The above eco-PDS items have been specified in Section 2.2, and this section shows how the detail design complies with them. Design experience and knowledge are important to provide input to meet the requirements of particular PDS items, such as the inputs to meet the requirement 'easy to repair the product or to recycle the product when it reaches its EoL stage' mentioned in the above PDS items Reduce the number of joints, Reduce the type of joints, Integration functions and Easy/fast disassembly.

\subsubsection{Utilization of Software Tools}

The following software tools are utilised to select/design the components of the table lamp prototype:

LED-driver selector web-based tool [48]: The driver selector tool helps to choose the optimum driver type (in terms of performance) according to specific LEDs type and performance. Once the brand and general type of components (LEDs and driver) were selected, the specific performance (model) of each type of component (LED and LED-driver) is confirmed based on the results of this tool to optimize the energy efficacy of the LED-LED driver system.

Thermal resistance datasheets: Thermal resistance datasheets were used to guide heat sink design and dimensions (Figure 6). The aluminum-made extruded heat sink initially designed by ONA was improved and optimized in a second iteration using the thermal resistance datasheets and the experience of external consultants. In the new design, the heat sink was made as part of the base. These changes were carried out to optimize the thermal performance of the heat sink.

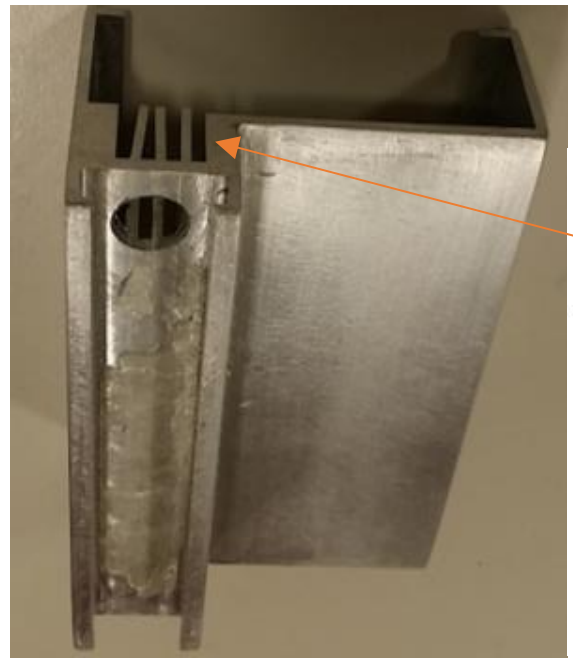

(a)

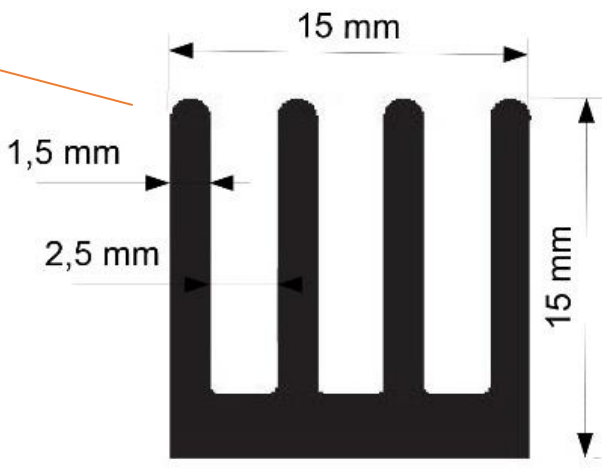

(b)

Figure 6. (a) Section view of the heat sink, (b) The base combined with the heat sink.

\subsection{Prototyping and Test}

In this stage, the manufactured prototype of the LED table lamp was tested and analysed to confirm that the final real product will pass all the tests and standards required. In so doing, software-based tools, hardware tools, and testing methods were used. To illustrate how the hardware tools and software tools were used in this phase, the light analysis (using goniometer) and the environment impact assessment (using LCA software) are presented in Sections 3.3.1 and 4, respectively.

The types of tests/analyses and tools used in this stage are briefly presented in this sub-section, as shown below. 


\subsubsection{Type of Tests/Analysis Involved}

Luminaire efficacy test: The efficiency and efficacy of the electronic components, subsystems and whole luminaire have been tested, measured and analysed: The efficiency of the driver is: $80.4 \%$, the LED and LED-driver system efficacy is: $112 \mathrm{Lm} / \mathrm{W}$, and the luminaire efficacy is: $26.08 \mathrm{Lm} / \mathrm{W}$. All these values were considered adequate in terms of energy-efficiency/efficacy.

Energy consumption test: The energy consumption of the luminaire is $5.6 \mathrm{~W}$. The measurement was taken after a 30 minutes-period to allow stabilization of the light source and lighting system energy consumption, and it was measured using a plug-in power meter [49].

Light analysis test: The Light performance of the luminaire was measured and analysed. The results are shown in Section 3.3.4 (Light analysis). To conduct the analysis and measurement several tools were used: Goniometer, Lux meter, Colorimeter, luminance meter, power meter and software-based tools (ProSource and Photometrics Pro). The results of the light performance of the Light sources (LEDs) alone were obtained using IES- LM-80 (IES, 2008a, 46) and TM-21 [47] test standards. The whole luminaire was tested following IES-LM-79 [50] standards.

Disassembly test: A disassembly test was carried out, where a user not familiar with the product was assigned to dismantle the product without instructions and with a common screwdriver as an only tool. The disassembly of the luminaire took around $5 \mathrm{~min}$ to take apart the main parts and components.

Environment impact assessment: The environmental impact of the luminaire was assessed and analysed. The results are shown in Section 4.

\subsubsection{Utilization of Software-Based Tools for the Analysis}

The following software tools were tilized:

ProSource [51]: This software can process the data captured by the goniometer, and translate it into EULUMDAT and IESNA photometric files that can be exported and analysed in Photometric analysis software. The light performance of the prototype was analysed to obtain the photometric files and calculate the efficacy of the luminaire.

Photometrics Pro [52]: This software can analyse the data contained in EULUMDAT and IESNA photometric files and translate it into graphs-results which show the light performance (e.g., light distribution, light intensity, beam angle) of the luminaire. After using the goniometer and ProSource software to obtain the EULUMDAT and IESNA files, these were used in Photometric Pro to analyse the light parameters and performance of the luminaire. Photometric files (via Photometrics Pro) ultimately can provide the light distribution of the luminaire, which can help to reduce the energy consumption. If the light distribution is known, the light output of the luminaire can be used more efficiently.

SimaPro [28]: This software is used to assess the environmental impact of the luminaire. To conduct the analysis, the prototype was dismantled, all the materials and substances were weighted, and the values were input into the software for analysis. The results of the assessment showed the total environmental impact of the total luminaire, each life cycle stage, and each process and material used. This information was used to determine which product life cycle stage and components had higher impact to inform possible further eco-design improvements to reduce the impact of the luminaire.

\subsubsection{Utilisation of Hardware-Based Tools for the Measurement}

The following hardware tools were tilized:

Source meter [53]: This is a tool used to measure the energy efficacy of the LED, LED driver and the system combining the LED and LED driver, among other functions. Once the LEDs and LED drivers were selected based on the criteria of energy efficacy, compliance with RoHS, reliability and serviceability; these were then tested with a source meter to confirm the energy efficacy of each component, and to find out the energy efficacy 
of the LED-LED driver system. The efficiency of the driver was $80.4 \%$, and the efficacy of the LED-LED driver system was $112 \mathrm{Lm} / \mathrm{W}$, which are good values.

Goniometer [29]: This tool is used to capture and measure the photometric data from the luminaire. The light performance of the prototype was measured using the goniometer, and photometric files (EULUMDAT and IESNA) were produced using ProSource software [51].

Illuminance meter [54]: This tool is used to measure the illuminance of the luminaire in lux. This value is necessary to carry out the analysis with the goniometer and obtain the photometric files. The illuminance of the prototype was calculated when the luminaire was mounted on the goniometer previous to conduct the full light goniometer analysis.

Colour meter [55]: This tool is used to measure the Correlated Colour Temperature (CCT) in ${ }^{\circ}$ Kelvin $\left({ }^{\circ} \mathrm{K}\right)$ of light sources or luminaires. The CCT of the luminaire was measured as part of the light analysis. CCT measurements are required because the colour temperature of the luminaire may differ from the one provided by the light source supplier when the light source is used within the luminaire whole system. The luminaire function is to provide a specific light quantity and quality, so both parameters need to be measured. These parameters also affect the energy used and the lifespan of the luminaire.

Power meter [49]: This tool is used to measure the energy consumption of the luminaire. The energy consumption of the prototype was measured before the light analysis with the goniometer. The measurement was carried out after $30 \mathrm{~min}$ of functioning in order to allow the luminaire consumption to stabilize.

\subsubsection{Light Analysis}

The light measurement and analysis (Figure 7) were conducted to assess the light performance and energy consumption of the whole luminaire. The light analysis provides photometric data about the light performance of the luminaire (Table 1), which can contribute to reducing energy use, because if the light distribution and intensity of the luminaire is known, the light can be used more efficiently. For example, the user can use the appropriate amount of light where it is needed, hence avoiding 'wasted' light and unnecessary energy consumption. In addition, the luminous flux (obtained in this light analysis) of the luminaire is required to calculate the luminaire efficacy.

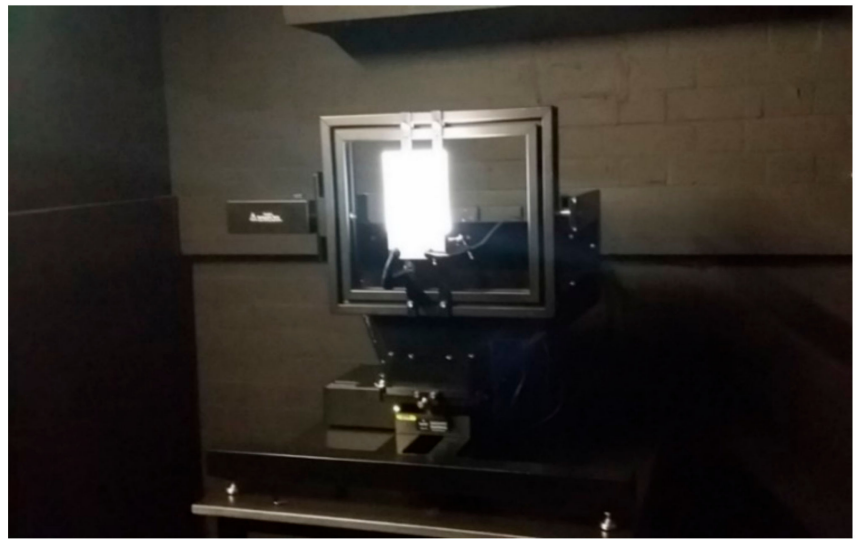

(a)

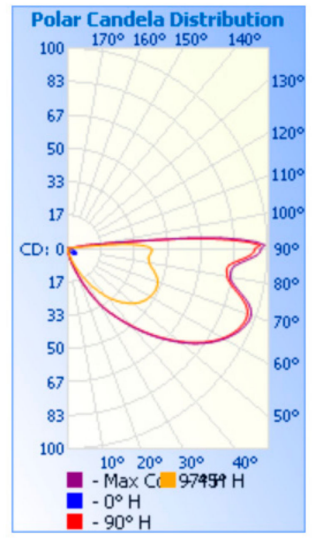

(b)

Figure 7. (a) The lighting analysis using Gonio photometer and (b) Polar candela diagram. 
Table 1. Light analysis results.

\begin{tabular}{ccc}
\hline Analysis Items & New LED Table Lamp & Benchmark Lamp \\
\hline LED useful lifetime & $93,000 \mathrm{~h}$. (L70) & $40,000 \mathrm{~h}$. (L70) \\
\hline Energy consumption (luminaire) & $5.6 \mathrm{~W}$ & $6.7 \mathrm{~W}$ \\
\hline Luminous flux (Luminaire) & $146.1 \mathrm{~lm}$ & $102.5 \mathrm{~lm}$ \\
\hline Luminaire efficacy & $26.08 \mathrm{~lm} / \mathrm{W}$ & $15.29 \mathrm{~lm} / \mathrm{W}$ \\
\hline Light source efficacy & $123 \mathrm{~lm} / \mathrm{W}$ & $56.66 \mathrm{~lm} / \mathrm{W}$ \\
\hline Luminous flux (Light source) & $30 \mathrm{~lm} \times 20 \mathrm{chips}=600 \mathrm{~lm}$ & $340 \mathrm{~lm}$ \\
\hline CRI (light source) & 80 & 80 \\
\hline CCT (light source) & $4000^{\circ} \mathrm{K}$ & $4000{ }^{\circ} \mathrm{K}$ \\
\hline Beam angle-vertical spread (luminaire) & $280.3^{\circ}$ & $102.1^{\circ}$ \\
\hline Beam angle- horizontal spread (luminaire) & $26.2^{\circ}$ & $96.3^{\circ}$ \\
\hline
\end{tabular}

Figure 7 shows the lighting measurement using Goniophotometer and measurement results shown in Polar candela diagrams. This figure graphically illustrates the light intensity at specific directions from nadir. Intensity is on the vertical axis, and radial lines indicate elevation angles from nadir to $180^{\circ}$. This diagram shows the maximum luminance angle is very close to $90^{\circ}$.

Table 1 shows the lighting measurement results of the LED table lamp developed by this research (new LED table lamp) and the benchmark LED table lamp (see Figure 8 and Section 4.1 for more information). The comparative results shown in Table 1 indicate that the LED table lamp developed by this research consumes less energy (5.6 vs. 6.7) and produces more light output (146.1 vs. 102.5), and consequently has higher 'luminaire efficacy' values (26.8 vs. 15.29) than the benchmark table lamp. Higher luminaire efficacy means producing more light with less energy, thus having less environmental impact. Other values such as colour temperature $\left(4000{ }^{\circ} \mathrm{K}\right)$ and CRI (80) are equal in both products, which is necessary for an objective LCA comparison. The luminous flux output of the new LED table lamp (taking into account the total amount of LED chips) is higher than the benchmark lamp (600 vs. 340). The light source lifespan is higher in the LED table lamp than that in the benchmark lamp $(93,000$ vs. 40,000) which means that the new LED table lamp has a longer lifespan than the benchmark lamp, although the actual number of hours depends on the operating conditions and the lamp design (thermal and electrical sub-systems design). It has to be noted that the lifespan has been calculated based on L70 tests standards, which means that after this time the LED has not failed, but its light output has been decreased below $70 \%$ of its initial light output.

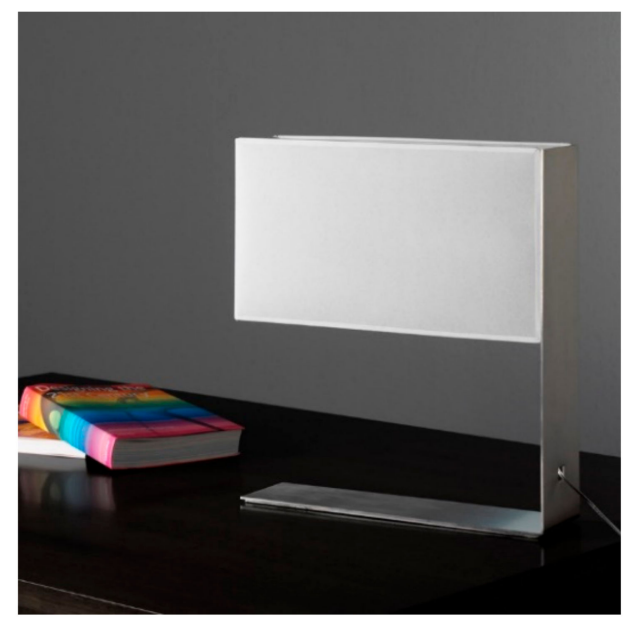

Figure 8. Benchmark lamp [31]. 
The lifespan of light source luminaires and Luminaire efficacy are the two key factors (from lighting measurement and analysis) that influence the environmental impact of an LED-based lighting product. Longer lifespans mean longer lasting products (and hence resource efficiency), and higher luminaire efficacy means more energy-efficient products that consume less energy whilst producing the same light output.

\subsection{Manufacture}

As a simple lighting product, the majority of parts and components of the LED table lamp developed by this research are provided by the suppliers and subcontractors, and the final product is assembled by Ona Product S. L.

To achieve the aim of increasing resource efficiency and reducing environmental impact, the product is manufactured in compliance with the following eco-PDS:

- Simplify the manufacturing process and use fewer processes in order to reduce energy consumption and waste.

- Use local suppliers in order to reduce transportation's impact on the environment

- Implement long term warranty (ONA provides: 5 years warranty)

- Provide exploded view with components and suppliers of each component to facilitate repair.

- Provide information about how and where to dispose the product to facilitate recycling and reuse.

- Encouraging online sale/purchasing of the products to reduce the retailers' and consumers' travel impact on the environment.

- Complies with the 'Waste of Electrical and Electronic Equipment (WEEE) directive to encourage the consumers to recycle the end of life products, and the manufacture reuses the parts, which are still functional, of the recycled products.

\section{Environmental Impact Life Cycle Assessment}

The assessment is conducted to evaluate the environmental impact of the new LED table lamp developed using the integrated approach of this study (so called new table lamp hereafter), taking into account the full product life cycle. The assessment is conducted in accordance with the international standards ISO 14044 [56], as detailed below.

\subsection{Aim and Scope}

The aim of the study is to assess and compare the environmental impact of the new LED table lamp as shown in Figure 2, in comparison with the benchmark LED table lamp shown in Figure 8 (so called benchmark lamp hereafter) which is also produced by ONA, using the LCA method.

As stated in the previous sections, the new table lamp is for general indoor (IP 20) lighting applications and its main materials used are PMMA and aluminum. A total of $50 \%$ of the product is made of recycled materials: the housing and heat sink area made of recycled aluminum. The product presents a simple structure with three main parts that can be disassembled fast and easily without special tools. The technical specifications of the LED table lamp can be seen in Table 2. 
Table 2. Technical specifications of new LED table lamp and benchmark lamp.

\begin{tabular}{ccc}
\hline Parameters & New Table Lamp & Benchmark Lamp \\
\hline Weight $(\mathrm{g})$ & 540 & 734 \\
\hline Luminous flux luminaire $(\mathrm{lm})$ & 400 & 440 \\
\hline Luminaire efficacy $(\mathrm{lm} / \mathrm{W})$ & 71.4 & 55 \\
\hline Power consumption of luminaire $(\mathrm{W})$ & 5.6 & 8 \\
\hline Color Correlated Temperature $(\mathrm{CCT})\left({ }^{\circ} \mathrm{K}\right)$ & 4000 & 4000 \\
\hline Color Render Index $(\mathrm{CRI})$ & 80 & 80 \\
\hline Luminaire useful lifetime $(\mathrm{h})$ & $93000(\mathrm{~L} 70)$ & $93000(\mathrm{~L} 70)$ \\
\hline
\end{tabular}

The benchmark lamp is also an LED-based table lamp (IP 20) for indoor lighting applications, and its main materials used are Plastic and Aluminum. The technical specifications of the benchmark lamp can be seen in Table 2 .

\subsection{System Boundaries}

The assessment comprises cradle-to-grave life cycle processes. The following life cycle stages are included in the assessment: manufacture, distribution, use and end of life. The packaging of the product and maintenance during the 'use stage' has not been included in the assessment.

The geographical area considered for the electrical grid used during the use phase, and the distribution (transport) of the product is Spain.

The average distribution distance considered from the factory to the point of sale or consumer is $316.9 \mathrm{~km}$ using trucks of 40 Tonnes.

The power consumption considered in the assessment for both luminaires during the 'use phase' is $400 \mathrm{~W}$ for the new table lamp and $440 \mathrm{~W}$ for the benchmark lamp. The useful lifespan considered is 93,000 $\mathrm{h}$ (L-70) for the new table lamp and 40,000 $\mathrm{h}$ (L-70) for the benchmark lamp, according to the LED lifespans provided by the LED supplier, which is obtained based on the TM-21 method. Although the LED supplier provides an estimated useful lifespan, it is probable that the real lifespan of the whole LED table tamp will be shorter, because the lifespan of the LED inside a lighting system and in real (non-controllable) operative conditions will not be the same (usually shorter) as the lifespan of the LED package in controlled LAB operative conditions. Nevertheless, we used those data as the useful life assumptions to compare the two LED table lamps.

Regarding the disposal stage, it is assumed that both LED table lamps are recycled following manual and mechanical processes: the luminaires are dismantled manually first, and the major plastic and metal parts and electronics are separated. The remaining parts go to automatic mechanical pre-treatment processes by, such as, shredder and metal/plastic types separators. The amount of recycled material at this stage is about $80 \%$. The manufacture and maintenance of the machines used during the whole recycling process are not considered. The remaining \% (dust) that is not recycled (loss) is collected and sold to another company, but since there is no data about this process it is not considered in the assessment.

\subsection{Functional Unit}

The functional unit used for the comparative assessment of the two luminaires is the production of $440 \mathrm{Lm}$ of lighting service for $93,000 \mathrm{~h}$ (L-70) with the following quality of light: Color Correlated Temperature $(\mathrm{CCT})=4000^{\circ} \mathrm{K}$, and Color Render Index (CRI) $=80$. Since the amount of lighting produced by the benchmark lamp is higher than the new table lamp (e.g., 440 vs. 400), the quantity of the new table lamp has to be adjusted, (e.g., multiplied or divided by a factor), to equal the same light (quantity) output as the benchmark lamp to be compared. To equal the quantity of light, the amount of light produced by the new table lamp $(400 \mathrm{~lm})$ has to be multiplied by 1.1 in order to produce 
the same light output as the benchmark lamp, and this is factored in the environmental impact assessment results of the new table lamp. The quality of light is the same in both luminaries, so there is no need to adjust it in this study; however, it could be adjusted by comparing the photopic curve with the light source specific spectral power distribution. Essentially, comparing the areas of both luminaires' light sources against the photopic curve gives the difference in efficacy.

\subsection{Life Cycle Inventory}

The Bill of Materials (BoM) of both luminaires used in the assessment is shown in Tables 3 and 4. These tables show the composition of both LED table lamps per material after the disassembly of both products by a company that works in the areas of recycling, dismantling and remarketing the scrap of electronic devices.

Table 3. Bill of Materials (BoM) of the new LED table lamp.

\begin{tabular}{cc}
\hline Material & Weight $[\mathbf{g}]$ \\
\hline Mixed cables/wires & 24 \\
\hline Aluminium Geschirr & 242 \\
\hline Plastics white & 192 \\
\hline ferrous scrap & 2 \\
\hline PWB class 1 & 6 \\
\hline PWB class 2 & 74 \\
\hline Total: & 540 \\
\hline
\end{tabular}

Table 4. BoM of the benchmark lamp.

\begin{tabular}{cc}
\hline Material & Weight $[\mathbf{g}]$ \\
\hline Mixed cables / wires & 66 \\
\hline Aluminium Geschirr & 78 \\
\hline Aluminium Profile & 132 \\
\hline Plastics white & 374 \\
\hline ferrous scrap & 4 \\
\hline Components containing precious metals & 14 \\
\hline PWB class 1 (LED PWB) & 8 \\
\hline PWB class 2 & 58 \\
\hline Total: & 734 \\
\hline
\end{tabular}

\subsection{Life Cycle Impact Assessment (LCIA) Method}

The LCIA method used in the assessment was the Eco-indicator 99 method (Hierarchist version) [57]. This LCIA method was selected because it provides a single score result which allows easier comparison between products. Using an end-point method based on a single score also facilitates decision making, since it is easier to see which product has higher impact. It also facilitates the communication of environmental impact results to stakeholders who are not familiar with impact categories, because it communicates the results using a single score.

In the Eco-indicator 99 method, normalization and weighting are performed at damage category level. There are three damage categories: Human Health (HH), Ecosystem Quality (EQ) and Resources (R), and eleven impact categories: Fossil Fuels, Minerals, Land Use, Acidification/Eutrophication, Ecotoxicity, Ozone Layer, Radiation, Climate Change, Respiratory Inorganics, Respiratory Organics and Carcinogens. 


\subsection{The LCIA Results and Discussion}

The results of the comparative assessment are presented in the following sections in several formats: Per end-point damage category (Section 4.6.1), per impact category (Section 4.6.2), and per process contribution (Section 4.6.3).

The unit used to quantify the environmental impact with the Eco-indicator 99 method is the Eco-indicator point (Pt.). The absolute value of the points is not very relevant as the main purpose is to compare the relative difference between products or components.

\subsubsection{Results per Damage Category}

The results (Figure 9 and Table 5) of the comparative assessment are presented in the following three end-point damage categories: Human Health (HH), Ecosystem Quality (EQ) and Resources (R).

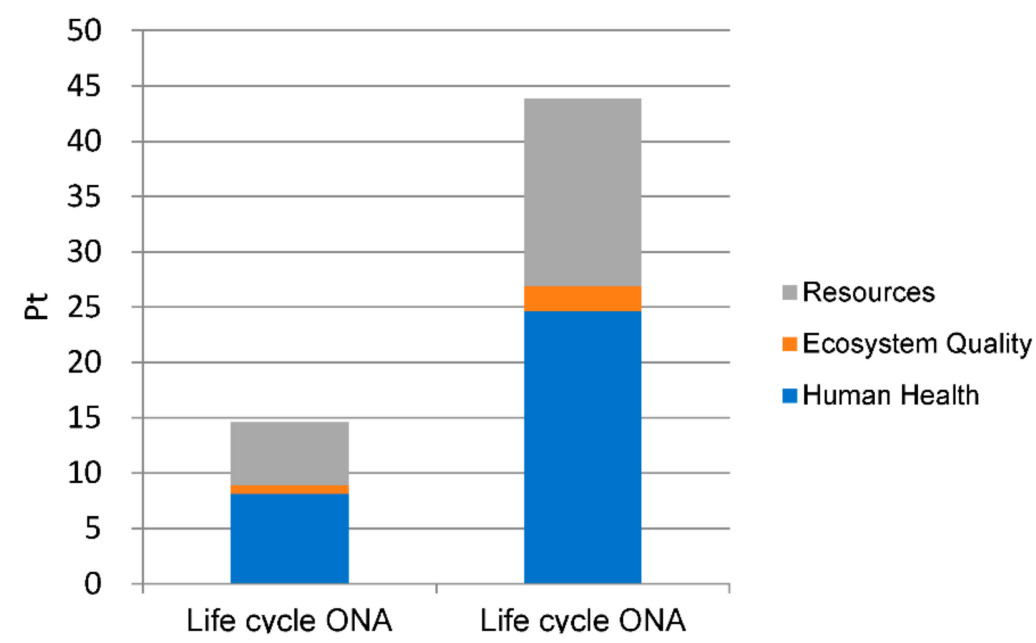

Figure 9. Results per damage categories of the new lamp (left) and benchmark lamp (right).

Table 5. Results per damage category.

\begin{tabular}{cccc}
\hline Damage Category & Unit & New Table Lamp & Benchmark Lamp \\
\hline Total & $\mathrm{Pt}$ & 14.608934 & 43.883193 \\
\hline Human Health & $\mathrm{Pt}$ & 8.1495463 & 24.665901 \\
\hline Ecosystem Quality & $\mathrm{Pt}$ & 0.74406188 & 2.2643321 \\
\hline Resources & $\mathrm{Pt}$ & 5.7153254 & 16.95296 \\
\hline
\end{tabular}

Results show (Figure 9 and Table 5) that the Benchmark luminaire (comparative product) has much higher environmental impact than the LED table lamp developed (43.88 vs. 14.60). The damage category with higher impact in both products is 'Human Health' (Demonstrator: 8.14 vs. Benchmark: 24.66), followed by 'resources' (Demonstrator: 5.71 vs. Benchmark: 16.95), and 'ecosystem quality' (Demonstrator: 0.74 vs. Benchmark: 2.26). In all damage categories the comparative product has higher values than the demonstrator.

\subsubsection{Results per Impact Category}

The results (Figure 10 and Table 6) of the comparative assessment are presented in the following eleven impact categories: Fossil Fuels, Minerals, Land Use, Acidification/Eutrophication, Ecotoxicity, Ozone Layer, Radiation, Climate Change, Respiratory Inorganics, Respiratory Organics and Carcinogens. 


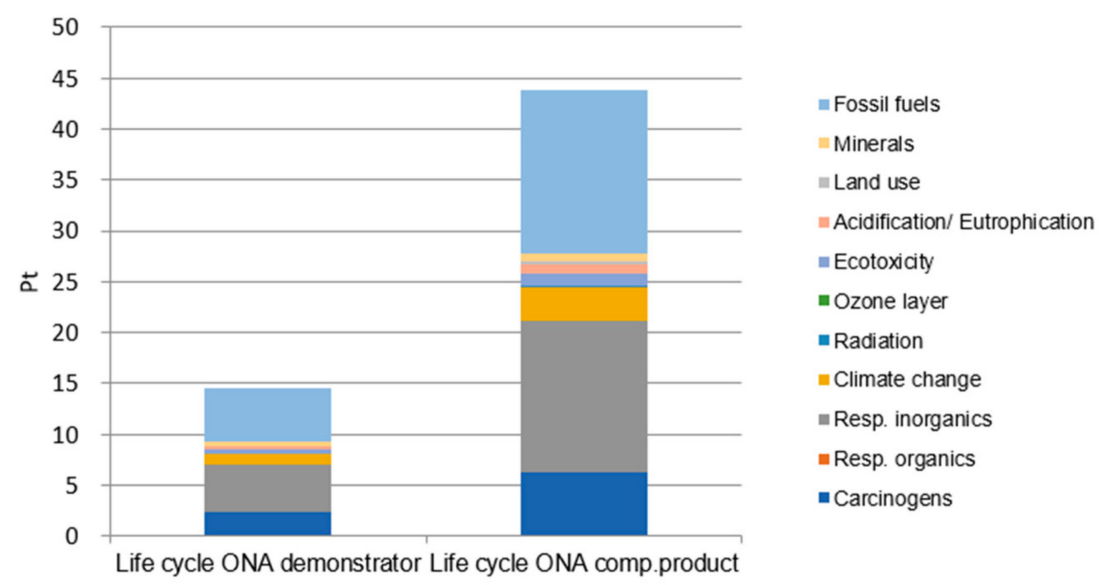

Figure 10. Results per impact category of the new lamp (left) and benchmark lamp (right).

Table 6. Results per impact category.

\begin{tabular}{cccc}
\hline Impact Category & Unit & New Table Lamp & Benchmark Lamp \\
\hline Total & $\mathrm{Pt}$ & 14.608934 & 43.883193 \\
\hline Carcinogens & $\mathrm{Pt}$ & 2.3647265 & 6.3496849 \\
\hline Resp. organics & $\mathrm{Pt}$ & 0.002005205 & 0.004417073 \\
\hline Resp. inorganics & $\mathrm{Pt}$ & 4.6684448 & 14.851242 \\
\hline Climate change & $\mathrm{Pt}$ & 1.0569012 & 3.2767993 \\
\hline Radiation & $\mathrm{Pt}$ & 0.057182945 & 0.18285652 \\
\hline Ozone layer & $\mathrm{Pt}$ & 0.000285721 & 0.000901272 \\
\hline Ecotoxicity & $\mathrm{Pt}$ & 0.3950197 & 1.1628713 \\
\hline Acidification/Eutrophication & $\mathrm{Pt}$ & 0.26057544 & 0.83088608 \\
\hline Land use & $\mathrm{Pt}$ & 0.088466741 & 0.27057473 \\
\hline Minerals & $\mathrm{Pt}$ & 0.36076051 & 0.81276345 \\
\hline Fossil fuels & $\mathrm{Pt}$ & 5.3545648 & 16.140197 \\
\hline
\end{tabular}

When we look at the results per impact category, we can see that the impact category with higher value for both products is 'fossil fuels' (the new lamp: 5.35 vs. the benchmark lamp: 16.14). This is due to the high demand for energy (and electricity production) to make the products function during their useful lifespan. The second impact category with higher impact is 'respiratory inorganics' (Demonstrator: 4.66 vs. Benchmark: 14.85), followed by: 'carcinogens' (the new lamp: 2.34 vs. the benchmark lamp: 6.34), 'climate change' (the new lamp: 1.05 vs. the benchmark lamp: 3.27), 'ecotoxicity' (the new lamp: 0.39 vs. the benchmark lamp: 1.16), 'Minerals' (the new lamp: 0.36 vs. the benchmark lamp: 0.81), 'acidification/eutrophication' (the new lamp: 0.26 vs. the benchmark lamp: 0.83), 'Land use' (the new lamp: 0.088 vs. the benchmark lamp: 0.27), 'radiation' (the new lamp: $0.05 \mathrm{vs.}$ the benchmark lamp: 0.18), 'respiratory organics' (the new lamp: 0.0029 vs. the benchmark lamp: 0.00441) and 'ozone layer' (the new lamp: 0.00028 vs. the benchmark lamp: 0.00090).

It has to be highlighted that it has been assumed that the benchmark luminaire has the same lifespan as the LED table lamp developed, but if the lifespan was less (which is likely due to the long lifespan of the demonstrator) the environmental impact of the benchmark would be even higher compared with the demonstrator total impact.

\subsubsection{Results per Process Contribution}

The results (Figures 11 and 12, and Table 7) of the comparative assessment are presented per process contribution. A 1\% cut off has been applied to the results displayed in 
the figures and tables to avoid showing the processes with minor contributions to the total impact of the product.

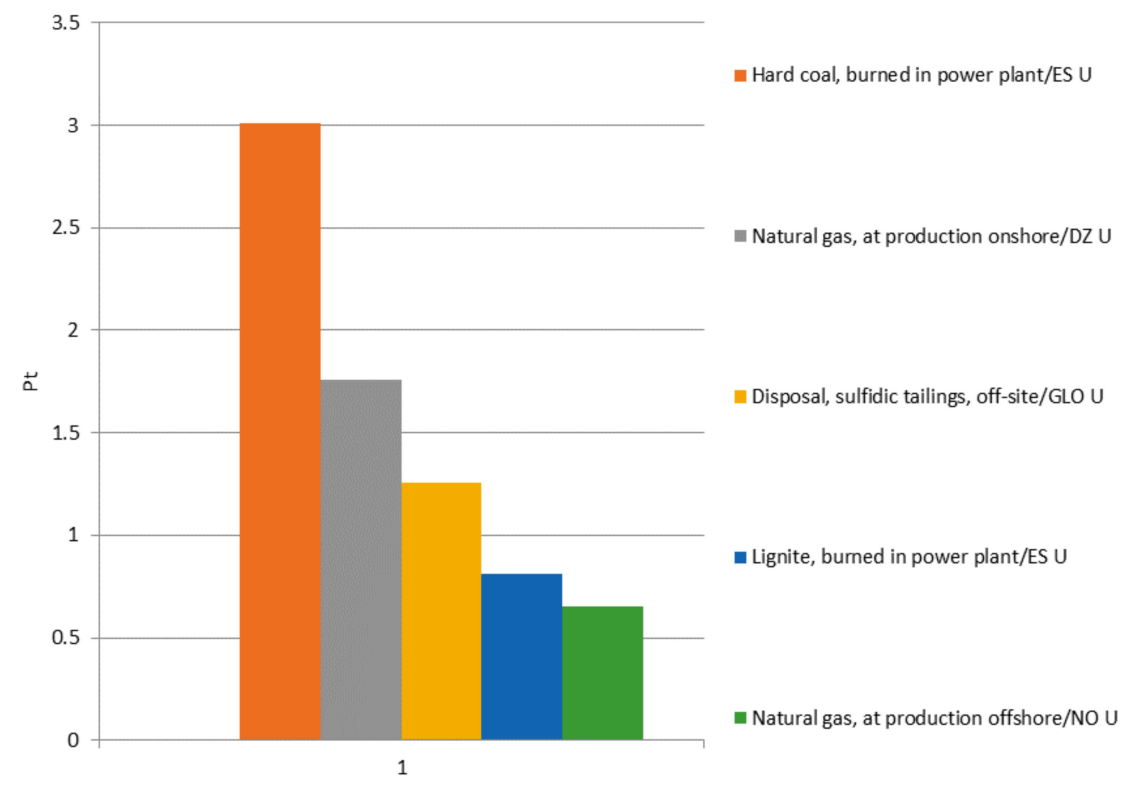

Figure 11. Results per process contribution of ONA LED table lamp.

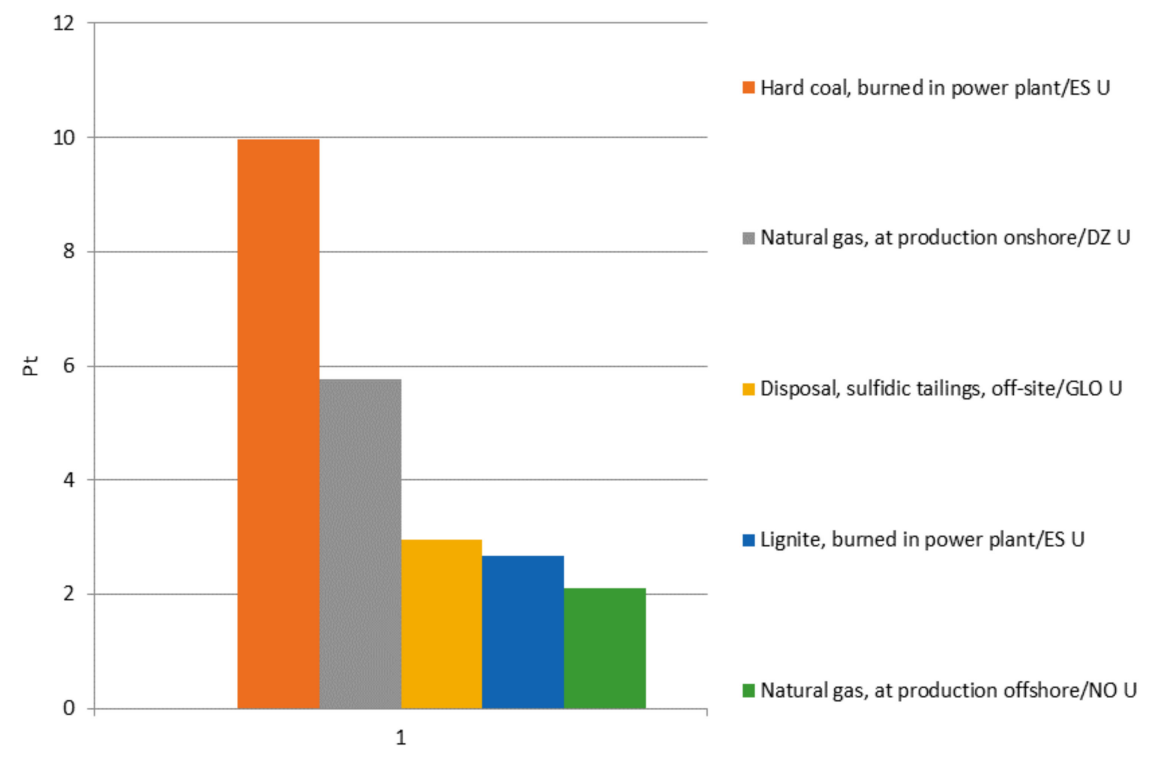

Figure 12. Results per process contribution of benchmark. 
Table 7. Results of the top 5 more impactful processes of the new lamp and the benchmark lamp.

\begin{tabular}{|c|c|c|c|c|c|}
\hline No. & Process & Database & Unit & New Lamp & Benchmark \\
\hline 1 & Hard coal, burned in power plant/ES U & Ecoinvent & $\mathrm{Pt}$ & $\begin{array}{c}3 \\
(25 \%)\end{array}$ & $\begin{array}{c}10 \\
(27 \%)\end{array}$ \\
\hline 2 & Natural gas, at production onshore/DZ U & Ecoinvent & $\mathrm{Pt}$ & $\begin{array}{c}1.8 \\
(14.5 \%) \\
\end{array}$ & $\begin{array}{c}5.8 \\
(15.6 \%) \\
\end{array}$ \\
\hline 3 & Disposal, sulfidic tailings, off-site/GLO U & Ecoinvent & $\mathrm{Pt}$ & $\begin{array}{c}1.3 \\
(10.4 \%)\end{array}$ & $\begin{array}{c}3 \\
(8 \%)\end{array}$ \\
\hline 4 & Lignite, burned in power plant/ES U & Ecoinvent & $\mathrm{Pt}$ & $\begin{array}{c}1 \\
(6.7 \%)\end{array}$ & $\begin{array}{c}2.7 \\
(7.2 \%)\end{array}$ \\
\hline 5 & Natural gas, at production offshore/NO U & Ecoinvent & $\mathrm{Pt}$ & $\begin{array}{c}1 \\
(5.4 \%)\end{array}$ & $\begin{array}{c}2 \\
(5.7)\end{array}$ \\
\hline
\end{tabular}

The top five processes with the highest environmental impact in the product lifecycle of the new lamp and the benchmark lamp (Figures 11 and 12 and Table 7) are: (1) 'Hard coal burned in power plant/ES U', where the new lamp developed has $33.3 \%$ less impact ( 3 vs. $10 \mathrm{pt}$ ) than the benchmark lamp (), (2) 'Natural gas, at production on-shore/DZ U, where the new lamp has $32.2 \%$ less impact (1.8 vs. $5.8 \mathrm{pt}$ ) than the benchmark lamp (3) 'Disposal, sulfidic tailings, off-site/GLO U' , where the new lamp has $23 \%$ less impact (1.3 vs. $3 \mathrm{pt}$ ) than the benchmark product, (4) 'Lignite, burned in power plant/ES U', where the new lamp has $27 \%$ less impact ( 1 vs. $2.7 \mathrm{pt}$ ) than the benchmark product, and (5) 'Natural gas, at production offshore/NO U', where the new lamp has $20 \%$ less impact ( $1 \mathrm{vs.} 2 \mathrm{pt}$ ) than the benchmark product. In all these five processes, which represent the processes with the highest impact, the benchmark lamp has substantially higher impact than the new lamp developed. All these processes are related with the production of electricity required to make the luminaire function during the 'use phase' over its lifespan. Since the lifespan considered $(93,000 \mathrm{~h})$ is quite long, the energy required is substantial, and the environmental impact of the processes related with the production of energy take the highest values. All the remaining processes have a minor relative impact in the total impact of both luminaires. When the relative impact of the processes are analyzed in relation to the total impact of each individual lamp, it is found that the relative impacts (\%) of each processes within the total impact of each lamp have similar relative values (e.g., process 1: $25 \%$ vs. $27 \%$ ), which means that the relative contribution to the total impact of each process for each lamp does not varies significantly between them, so the difference in total impact between the new lamp and the benchmark lamp is distributed among the same processes both luminaires evenly.

\section{Discussion}

The discussion about the LCIA results has been given in Section 4.6. This section is to discuss the eco-design aim with related issues and the limitations and future work.

\subsection{Eco-Design Aims with Related Issues}

As stated in the Introduction section at the beginning of this paper, the eco-design defined in this research is to create products aimed at (1) reducing the products' environmental impacts and (2) keeping the quality level according to the products' ideal usage. Both the aims have been achieved in the development of the new LED lamp.

The achievement of the aim 'reducing the environmental impact' is confirmed by the compliance with the eco-PDS and the comparative assessments of the new LED table lamp with the benchmark lamp, using life cycle analysis and other performance criteria, e.g., luminous efficacy and energy consumption. The results show that the new LED table lamp reduced its environmental impact and achieved higher energy-efficiency values compared with the benchmark LED table lamp. 
The achievement of the aim 'keeping the quality level' is confirmed by the results of several tests conducted, as detailed in Section 3.3, which have ensured the lighting quality of the new LED table lamp.

The eco-PDS is established at the beginning of eco-design and then each subsequent stage complies with the eco-PDS throughout the eco-design process. Although the PDS method has been utilised in product design for many years, the incorporation of ecoconstrains in the PDS has not been given enough attention, such as those [14-17] cited in the PDS literature review given in the introduction section. The existing research found in the literature, such as those [18-21] reviewed in the introduction section, focuses in particular on some aspects of the environmental impact of the lighting products, such as energy consumption, eco-efficiency, eco-cost and LCA. None of them considered the full list of eco-PDS. Different from the existing research, this research developed the eco-PDS covering the whole eco-design process, as shown in Section 2.2. Because the PDS is a control mechanism in the design process, the compliance with the eco-PDS ensures that the product achieves the expected functions with the eco-features. This has been illustrated in Section 3 with the new LED table lamp.

For a successful eco-design, the designed product not only has to reduce its impact on the environment, but also has to achieve its required quality according to the products' ideal usage; otherwise, the product will not be accepted by the consumers. This is crucial for the product to secure its marketplace. In addition to the reduced environmental impact and achieving the required lighting quality, the new LED lamp has a USB socket, as shown in Figure 2, which is convenient to charge mobile phones and tablets at the use stage of the lamp, but the benchmark lamp does not have this additional function, and, hence, the new LED lamp is more attractive to the consumers than the benchmark lamp.

\subsection{Limitations and Future Work}

The limitations of this study are mainly due to the limited validation that provided a single case study. The approach should be applied and tested to more LED-based lighting products by product designers working in different companies, which would allow the checking of not only the validity of the approach, but also how the approach works with different types of end-users, with different experience, capacity and capabilities. Further validation will also provide useful feedback and insights to improve and refine the approach further and make it more usable to achieve the impact (e.g., environmental impact reduction in LED lighting products) expected by the application of this type of approaches.

This study focused on the environmental impact of the lighting product, although the LCA results include human health as one of the three end points. It could be further extended to product sustainability which covers environmental, social and economic impacts. To do so, social life cycle assessment could be conducted, as well as to consider the product's cost, market values and other aspects of economic impact.

The eco-design conducted in this research covers the product design and manufacture stages of the product life cycle. The future research could cover the remaining stages of the product life cycle including retail, consumption, repair, maintenance, recycling, reuse and end-of-life treatment of the product. This will complete the product lifecycle loop with the sustainability consideration, in order to fulfil an integrated sustainability investigation through the whole life cycle of lighting products. The checklist method presented in [58] for sustainable product development can be adapted, which allows the qualitative assessment of environmental, economic and social aspects during the early phases of product development while considering a full life cycle perspective, and the check list can be considered to improve the eco-PDS.

\section{Conclusions}

This research developed an integrated approach for the eco-design of LED-based lighting products. In addition to product design specification, conceptual design and detail design, the eco-design also includes prototyping, testing and manufacture, the results of 
which validate the designed product. Several tools and methods are applied at different stages of the eco-design process, in order to reduce the product's impact on the environment, while ensuring the product quality. Such an integrated eco-design approach specially focusing on lighting products has not been seen before, and, hence, it is a novel contribution to the eco-design of lighting products.

Eco-PDS, i.e., product design specification reflecting the eco-features of the product is developed, which the product has to comply with at each stage of the eco-design process. Although the PDS method has been utilised in product design for many years, the incorporation of eco-constrains in the PDS has not been given enough attention. Therefore, this is another novelty in eco-design.

An LED table lamp was successfully developed by the application of the integrated eco-design approach. The application illustrated how relevant methods and tools, as well as the eco-PDS, were utilized throughout the eco-design process.

The LCA of the developed LED table lamp has been conducted in comparison with a benchmark LED table lamp. The assessment results showed that the new LED table lamp developed has substantially less environmental impact than the benchmark LED table lamp, (14.608934 vs. 43.883193), which validates the approach.

Author Contributions: Conceptualization, D.S. and J.L.C.; methodology, D.S., J.L.C. and X.X.; investigation, J.L.C., X.X. and D.S.; writing—original draft preparation, D.S.; writing—review J.L.C. and D.S.; editing, D.S.; visualization, J.L.C. and X.X.; research supervision, D.S.; funding acquisition, D.S. All authors have read and agreed to the published version of the manuscript.

Funding: This research was funded by the European Commission 7th Framework Programme for the cycLED project, grant agreement number 282793.

Informed Consent Statement: Informed consent was obtained from all subjects involved in the study.

Data Availability Statement: Data is not publicly available, though the data may be made available on request from the corresponding author.

Acknowledgments: The authors are grateful for the support received from ONA Product S.L.

Conflicts of Interest: The authors declare no conflict of interest.

\section{References}

1. UNEP. Accelerating the Global Adoption of Energy-Efficient Lighting-United for Efficiency. 2017. Available online: https: / / united4efficiency.org/resources/accelerating-global-adoption-energy-efficient-lighting/ (accessed on 15 November 2020).

2. IEA (International Energy Agency). 2014. Available online: https:/ / www.iea.org/topics/energyefficiency/lighting/ (accessed on 10 November 2017).

3. GLC. Global Lighting Challenge Campaign (GLC) Fact Sheet. May 2018. Available online: http:/ /www.cleanenergyministerial. org/sites/default/files/2018-07/GLC\%20fact\%20sheet\%20\%28May\%202018\%29.pdf (accessed on 24 November 2020).

4. Su, D. Introduction and Sustainable Product Development. In Sustainable Product Development; Su, D., Ed.; Springer: Cham, Switzerland, 2020; pp. 1-12. [CrossRef]

5. European Commission. 'Sustainable Product Policy', EU Science Hub, Last Updated 12 December 2018. 2018. Available online: https:/ / ec.europa.eu/jrc/en/research-topic/sustainable-product-policy, (accessed on 24 November 2020).

6. Olesen, J. Concurrent Development in Manufacturing-Based Upon Dispositional Mechanisms; Technical University of Denmark: Kongens Lyngby, Denmark, 1992.

7. Graedel, T.E.; Comrie, P.R.; Sekutowski, J.C. Green Product Design. ATET Tech. J. 1995, 74, 17-25. [CrossRef]

8. McAloone, T.C.; Bey, N. Environmental Improvement through Product Development: A Guide; Danish Environmental Protection Agency: Copenhagen, Denmark, 2009.

9. Church, T.R. Back to the Drawing Board: How Good Design Can Eliminate Waste, the Guardian. 3 September 2014. Available online: https:/ /www.theguardian.com/sustainable-business/2014/sep/03/good-design-eliminate-waste (accessed on 20 November 2019).

10. Revol. What Does Eco Design Mean? Ma Maison Revol Articles. 12 May 2020. Available online: https://www.mamaisonrevol. com/what-does-eco-design-mean / (accessed on 20 December 2020).

11. Youmatter. Eco Design: Definition, Examples, Principles. Last Modified on 12 February 2019. 2019. Available online: https: / /youmatter.world/en/definition/definition-eco-design-examples-definition/ (accessed on 20 December 2020).

12. Charter, M. Designing for the Circular Economy; Routledge: Abingdon, UK, 2019; p. 21. ISBN 9781138081017. 
13. NIBUSINESS INFO, (n.d.). Ecodesign Principles, a Free Service Offered by Invest Northern Ireland, an Official Online Channel for Business Advice and Guidance in Northern Ireland. Available online: https:/ / www.nibusinessinfo.co.uk/content/whatecodesign (accessed on 24 December 2020).

14. Pugh, S. Total Design-Integrated Methods for Successful Product Engineering; Prentice Hall: London, UK, 1991.

15. Ulrich, K.T.; Eppinger, S.D. Product Design and Development; McGraw Hill: Singapore, 2008.

16. Budynas, R.G.; Nisbett, J.K. Shigley's Mechanical Engineering Design, 10th ed.; McGraw-Hill: Singapore, 2019.

17. Cross, N. Engineering Design Methods, 4th ed.; John Wiley and Sons Ltd.: Chichester, UK, 2008.

18. Zehra, F.; Korkmaz, K.A.; Ahmeda, M.S. Sustainable Lighting System for University Buildings. J. Build. Sustain. $2018,1,12-22$.

19. Balocco, C.; Volante, G. Lighting Design for Energy Sustainability, Information, and Perception. A Museum Environment as a Case Study. Sustainability 2018, 10, 1671. [CrossRef]

20. Klaassen, N.; Scheepens, A.; Flipsen, B.; Vogtlander, J. Eco-Efficient Value Creation of Residential Street Lighting Systems by Simultaneously Analysing the Value, the Costs and the Eco-Costs during the Design and Engineering Phase. Energies 2020, 13, 3351. [CrossRef]

21. Wang, S.; Su, D.; Wu, Y.; Chai, Z. Lifecycle assessment of domestic lighting products. Euro-Mediterr. J. Environ. Integr. 2020, 5, 41. [CrossRef]

22. Richter, J.L.; Tähkämö, L.; Dalhammar, C. Trade-offs with longer lifetimes? The case of LED lamps considering product development and energy contexts. J. Clean. Prod. 2019, 226, 195-209. [CrossRef]

23. Shahzad, K.; Čuček, L.; Sagir, M.; Ali, N.; Rashid, M.I.; Nazir, R.; Nizami, A.S.; Al-Turaif, H.A.; Ismail, I.M.I. An ecological feasibility study for developing sustainable street lighting system. J. Clean. Prod. 2018, 175, 683-695. [CrossRef]

24. Katzin, D.; Marcelis, L.F.; Van Mourik, S. Energy savings in greenhouses by transition from high-pressure sodium to LED lighting. Appl. Energy 2021, 281, 116019. [CrossRef]

25. Zhang, K.; Kleit, A.N.; Nieto, A. An economics strategy for criticality-Application to rare earth element Yttrium in new lighting technology and its sustainable availability. Renew. Sustain. Energy Rev. 2017, 77, 899-915. [CrossRef]

26. European Commission. Waste Electrical and Electronic Equipment (WEEE) Directive. 2012. Available online: http:/ / eur-lex. europa.eu/legal-content/EN/TXT/?qid=1396281707331\&uri=CELEX:32012L0019 (accessed on 22 November 2020).

27. UL. UL Standard 'UL8750-2009: Light Emitting Diode (LED)' Equipment for Use in Lighting Products. 2009. Available online: http:/ / ulstandards.ul.com/standard / ?id=8750_1 (accessed on 20 March 2019).

28. PRe Consultants. SimaPro Software. 2015. Available online: http://www.pre-sustainability.com/simapro (accessed on 20 March 2019).

29. Radiant Vision Systems. Goniometer PM-NFMS. 2015. Available online: http://www.radiantvisionsystems.com/products/pmnfms (accessed on 20 March 2019).

30. Casamayor, J.L.; Su, D. Review of Directives, Regulations and Standards Related to Sustainable Product Design and Manufacture. In Sustainable Product Development: Tools, Methods and Examples; Su, D., Ed.; Springer Nature: Cham, Switzerland, 2020; pp. 15-17.

31. Su, D.; Anbalagan, A.; Xu, X.; Ren, Z. LED Toolbox: Toolbox Aiming to Increase Resource Fficiency of LED Products; Deliverable 3.2 of EU FP7 cycLED Project; Nottingham Trent University: Nottingham, UK, 2015.

32. cycLED. Cycling Resources Embedded in Systems Containing Light Emitting Diodes-An International Collaborative Project Supported by the European Commission FP7 Programme. Available online: https://cordis.europa.eu/project/id/282793 (accessed on 22 November 2020).

33. Ona. Available online: https:// onaemotion.com/en/lamp-shop-online/ (accessed on 22 November 2020).

34. European Commission. Energy Labelling Directive (2010/30/EU). 2010. Available online: http:/ / eur-lex.europa.eu/legalcontent/EN/NOT/?uri=CELEX:32010L0030 (accessed on 22 November 2020).

35. European Commission. Restriction of Hazardous Substances (Rohs) Directive. 2011. Available online: http:/ / eur-lex.europa.eu/ legal-content/EN/TXT/?uri=CELEX:32011L0065 (accessed on 25 March 2015).

36. European Commission. Ecodesign Directive (2009/125/EC). 2009. Available online: http:/ / ec.europa.eu/enterprise/policies / sustainable-business/documents/eco-design/legislation/framework-directive/index_en.htm (accessed on 22 November 2020).

37. Samsumg. LED: LM 561A Middle Power LED. 2015. Available online: http://www.samsung.com/global/business/led/ lighting/component/middle-power/overview / 97 (accessed on 20 November 2019).

38. Lumotech. LED Light Mini-Series L05050/L05150. 2015. Available online: http://www.lumotech.com/Products/-12W/L05021 -LED-driver-12W-3-32-Vdc-350-700-mA-9 (accessed on 16 April 2016).

39. European Commission. Registration, Evaluation, Authorisation and Restriction of Chemicals (REACH) Directive. 2010. Available online: http:/ / ec.europa.eu/enterprise/sectors/chemicals/reach/index_en.htm (accessed on 22 November 2020).

40. BSI (British Standard Institute). BS EN 55015:2013. Limits and Methods of Measurement of Radio Disturbance Characteristics of Electrical Lighting and Similar Equipment. 2013. Available online: http://shop.bsigroup.com/SearchResults/?q=EN55015 (accessed on 22 November 2020).

41. BSI (British Standard Institute). BS EN 61000-3-2:2014. Electromagnetic Compatibility (EMC). Limits. Limits for Harmonic Current Emissions (Equipment Input Current $\leq 18$ A per Phase). 2014. Available online: http://shop.bsigroup.com/SearchResults/?q= EN61000 (accessed on 22 November 2020). 
42. BSI (British Standard Institute). BS EN 61347-2-13:2014. Lamp Controlgear. Particular Requirements for d.c. or a.c. Supplied Electronic Controlgear for LED Modules. 2014. Available online: http:/ / shop.bsigroup.com/SearchResults/?q=EN61347-2-13 (accessed on 22 November 2020).

43. BSI (British Standard Institute). BS EN 61347-1:2008+A2:2013. Lamp Controlgear. General and Safety Requirements. 2013. Available online: http:/ / shop.bsigroup.com/SearchResults/?q=EN61347-1 (accessed on 22 November 2020).

44. BSI (British Standard Institute). BS EN 61547:2009. Equipment for General Lighting Purposes. EMC Immunity Requirements. 2009. Available online: http:/ / shop.bsigroup.com/SearchResults/?q=EN61547 (accessed on 22 November 2020).

45. BSI (British Standard Institute). BS EN 62384:2006+A1:2009. DC or AC supplied Electronic Control Gear for LED Modules. Performance Requirements. 2006. Available online: http://shop.bsigroup.com/SearchResults/?q=EN62384 (accessed on 22 November 2020).

46. IES (Illuminating Engineering Society). IES-LM-80-08 Test Standards. 2008. Available online: https://www.ies.org/store/ product/approved-method-measuring-lumen-maintenance-of-led-light-sources-1096.cfm (accessed on 10 April 2019).

47. IES (Illuminating Engineering Society). TM-21-11 Test Standards. 2011. Available online: http://www.ies.org/store/product/ projecting-long-term-lumen-maintenance-of-led-light-sources-1253.cfm (accessed on 10 April 2019).

48. Future Lighting Solutions Inc. LED Driver Selector On-Line Web-Based Application. 2015. Available online: http://www. futurelightingsolutions.com/en/development/Pages/index.aspx (accessed on 25 March 2015).

49. Maplin. Plug-In Power Meter. 2015. Available online: http://www.maplin.co.uk/p/15a-plug-in-energy-saving-monitor-161aq (accessed on 30 March 2019).

50. IES (Illuminating Engineering Society). TM-79-08 Test Standards. 2008. Available online: https://www.ies.org/store/ product/approved-method-electrical-and-photometric-measurements-of-solidstate-lighting-products-1095.cfm (accessed on 10 April 2018).

51. Radiant Vision Systems. ProSource Software. 2015. Available online: http://www.radiantvisionsystems.com/products/ application-software (accessed on 30 March 2019).

52. Photometricpro.com. Photometrics Pro Software. 2015. Available online: http://www.photometricspro.com/ (accessed on 30 March 2019).

53. Keithley. 2440 5A Source Meter. 2015. Available online: http://www.keithley.co.uk/products/dcac/specialtysystems/ optoelectronics /?mn=2440 (accessed on 30 March 2018).

54. Konica Minolta. Illuminance Meter T-10 A. 2015. Available online: http:/ / www.konicaminolta.eu/en/measuring-instruments / products/light-display-measurement/illuminance-meters/t-10a/introduction.html (accessed on 30 March 2019).

55. Konica Minolta. Illuminance colour meter CL-200 A. 2015. Available online: http:/ / www.konicaminolta.eu/en/measuring-instruments/ products/light-display-measurement/illuminance-colour-meters/cl-200a/introduction.html (accessed on 22 November 2020).

56. ISO (International Standardisation Organisation). ISO 14044:2006_Environmental Management: Life Cycle Assessment: Requirements and Guidelines. 2006. Available online: https://www.iso.org/standard/38498.html?browse=tc (accessed on 3 March 2018).

57. Goedkoop, Mark. Eco-Indicator 99 LCIA. 2000. Available online: http://www.pre-sustainability.com/download/EI99_ methodology_v3.pdf (accessed on 22 November 2020).

58. Schöggl, J.P.; Baumgartner, R.J.; Hofer, D. Improving sustainability performance in early phases of product design: A checklist for sustainable product development tested in the automotive industry. J. Clean. Prod. 2017, 144, 1602-1617. [CrossRef] 